\title{
Doctors and Counsellors: Collaboration or Conftict?*
}

\author{
By AUdrey Newsome
}

The practice of Counselling is a social movement which has developed in momentum and strength in the 1970s. Like other movements, it is observed by many and understood by few. It is acclaimed by those who see in it the possibility of at least alleviating human problems, at best as an aid to enable individuals to make the most of their potential in a highly complex world which at one and the same time is full of choice and opportunity and of confusion, frustration and insecurity.

\section{My own entry lnto counceling}

Recognising that my attitude to the counselling movement is highly personal and influenced by the position I occupy as a counsellor, perhaps I may be permitted to describe how I came to do the kind of work in which I am employed in higher education. For some years I worked with young people in grammar and independent schools, attempting to help them with educational and occupational choice. My experience of work in boarding schools in particular led me to seek further training - I was not understanding the needs of my clients. Although my task seemed clear-cut: to discover the stage the young persons had reached in occupational choice and to help them take a further step on the road to its implementation, I was often frustrated in achieving my goals for reasons I failed to understand.

In the boarding schools where I worked there were many pupils who needed a sympathetic ear to enable them to talk about more immediate and pressing concerns of a totally different order from those of occupational choice. Concern about themselves and their relationships were often far more pressing, and their preoccupations precluded proper consideration of educational or occupational choice, which often seemed remote and unimportant.

My later study of adolescent development led me to see that questions about educational, vocational and personal development are strongly inter-related to the extent that the division of counselling into water-tight boxes concerned with only one aspect of the client's life is, for me, totally false in the educational setting in which I work. Furthermore, to label young people as sick because they are worried about some aspect of their development is to fail to understand that different strands of personality develop at different times.

Each of these strands is important, although past emphasis on education meant a focus on intellectual rather than emotional development. A deficit in the development of 'personality' was transferred to the charge of the clinic and removed from the responsibility of the school. Nevertheless, it would be wrong to deny that a small percentage of young people are sufficiently disturbed to need psychiatric or "Based on a paper delivered to the Psychotherapy Section on 9 January 1980. psychotherapeutic treatment. Differentiating between those in need of psychiatric treatment and those for whom counselling help is appropriate is sometimes difficult. Within this area there lies potential for collaboration or conflict. Clear definition of the doctor's responsibilities is difficult, and similarly with the counsellor. I leave you to specify the doctor's role, I will try to define that of the counsellor.

\section{The role of the conneellor}

The role of the counsellor depends not only on the setting in which he practises but also on the way in which the employing institution has defined its need for him. All too often no clear definition has been made and the counsellor himself has had to shape his role according to qualification and predilection.

In our book, Student Counselling in Practice, colleagues and I conclude that it is easier to say what counselling is not. It is not: giving advice, persuading or convincing; interrogation; poychoanalysis; or a pale imitation of the practices developed by psychoanalysts. We tried, too, to look at differences between psychotherapy and counselling which cause many people considerable difficulty.

I see myself firmly identified as a counsellor and, as such, I see myself principally concerned with a wide range of people who have problems relating to normal development and functioning in (for me) an educational setting. Of course I am dealing with people who are experiencing moderate or even severe personality problems, but the emphasis of my work is to enable the normally developing young person to make the most of his opportunities. I use the word 'enable', not 'treat'. I work in a Service, not a Clinic. My clients are 'students' or 'people', not 'patients'. I look for strengths and health, not for a diagnosis or a label.

I have described counselling elsewhere (Crown, 1976) as the application of intelligent, educated love to individuals or groups seeking help in their personal development or in problem solving. I realise that this definition runs the risk of being undervalued or even ridiculed. I mean by 'love' the capacity to feel and demonstrate profound respect for another individual, his integrity and his capacity to become self-directing.

The definition of counselling recently published by the British Association for Counselling states:

'People become engaged in counselling when a person occupying regularly or temporarily the role of counsellor offers or agrees explicitly to offer time, attention and respect to another person or persons temporarily in the role of client.

The task of counselling is to give the client an opportunity to explore, discover and clarify ways of living more resourcefully and toward greater well-being.' 
The Brtish Association for Counselling

As counsellors we have only just begun the task of defining our work, establishing ethical standards of practice, of explaining ourselves to our clients, our institutions, and more broadly, to the public. Only two years ago, the British Association for Counselling was established out of the Standing Conference for the Advancement of Counselling, set up eight years earlier under the wing of the National Council of Social Service. Current membership is 2,400, with over 190 member organisations. Its seven divisions are: pastoral; family/personal/marital/sexual; youth; work; educational; medical; and student. Its objectives are:

a. to promote and provide education and training for counsellors working in either professional or voluntary settings, whether full or part-time, with a view to raising the standards of counselling for the benefit of the community, and in particular of clients.

b. to advance the public's knowledge of the counsellor's contribution and in particular to meet the needs of those whose development and functioning are impaired mentally, physically or socially.

The most recent development in the Association is regional branches; these have grown in response to counsellor's needs to obtain support for their work and to increase knowledge and skills. The potential for these groups to affect the mental health of the communities in which they work is enormous, and I would hope that psychiatrists will contribute to their work.

\section{Mental in health in the community}

I need hardly remind psychiatrists of the prevalence of mental ill-health in the community, demonstrated by the demands on your time and expertise, the length of waiting lists, and the National Health Service drug bill.

There is evidence that mental illness occurs more commonly at periods of change, e.g. entry into school or job, marriage, parenthood and retirement. If the counsellor's concern is with promotion of health and with assisting people to cope with their own development, he must not only become familiar with techniques of counselling but also understand human growth and development and the nature of crisis and crisis-intervention. As defined by Erikson (1968), crisis should not connote impending catastrophe but a 'necessary turning point, a crucial moment, when development must move one way or another, marshalling resources of growth, recovery and further differentiation'. This view enables counsellor and client to regard the 'crisis' as an opportunity to utilize the energy which it produces in the client in constructive ways.

\section{Counselling in the next decade}

We are now in the 1980 s, which seem to promise little but uncertainty and insecurity. But they also offer challenge! Toffler, in Future Shock, says that in order to help tide millions of people over the difficult transitions they are likely to face we shall be forced to 'deputize' large numbers of professionals-businessmen, students, teachers, workers and others- to serve as 'crisis counsellors'. He predicts that they will need to be expert, not in a conventional discipline such as psychology, but in understanding and helping people with the special transitional problems which will be forced on them by the fracturing of traditional expectations of work and family life. I am bound to agree.

\section{Counselling and doctors}

My behaviour in preparing this paper has been of interest to me, and from it I hope I have learned something useful. I was surprised, not to say astonished, to be invited. I felt pleased but also anxious and threatened. I expected my audience to consist of some I know to be well-disposed to counselling, but also of some who are suspicious if not antagonistic. I am strongly identified with the counselling movement and concerned that an opportunity such as this should be used as well as possible. I am conscious that the training of counsellors is quite different from that of doctors. It is usually far shorter and its style and content different. The language we use and the tools at our disposal differ. In general, we as counsellors, work with 'clients' in a service centre, rather than with patients in a clinic. In the course of our work, we meet people who are more disturbed than the patients identified for treatment by the psychiatrist. We then feel vulnerable, anxious and often inadequate. At the same time, we have ambivalent feelings about forms of medical treatment, their uses and disadvantages-for example, ECT and some types of drugs. If we feel anxious and threatened, how do you as psychiatrists feel about us, after your lengthy and rigorous training with the different expectations which many patients have of you, and with the demands on your time and expertise?

With such different training and yet an overlap in the work we do, it is not surprising that there is potential for conflict, which, if unrecognized and not dealt with, is counter-productive. Such problems are not confined to the relationship between the professions; they exist internally within each, as I am sure we are all aware. Problems of status bedevil us all. For some it is more prestigious to treat the deeply disturbed person on a long-term basis than to deal briefly with someone in need of less help. For others, it may be more important to identify as a psychotherapist than as a counsellor, or to work in a college rather than in a clinic. Whatever our predilection, it is obvious that while the core of our role as psychiatrist, counsellor, priest, or teacher is different, there is an area of overlap in our work which will be done better if we can learn from one another.

Most doctors are well aware that large numbers of patients present to them problems which require counselling help. Some maintain that it is only the doctor, with his knowledge of the whole human being, who can undertake this counselling; also, that if one is a doctor, one is also ipso facto 
a counsellor. If such doctors fail to counsel, the problem, they maintain, is time; given more time, all would be possible.

Students selected for medical training are usually not selected for their counselling potential, nor does their education, in general, produce a professional whose orientation is that of the counsellor. The training is designed to produce doctors, not counsellors. One by-product of training and practice can be an arrogance and a distance which are certainly at odds with a counselling approach. Attention and respect, the other ingredients intrinsic to counselling, are not always demonstrated by doctors in general practice or in hospitals. Many doctors may be effective in their specialized work, but are temperamentally and attitudinally unsuited to a counselling role, and lack any proper preparation for it. The same may of course be true of people working in other settings such as in education or in the church.

For the doctor with the potential and the wish to assume a counselling role, counsellors have something to offer. They have also shown the contribution they can make to the doctor's work in, for example, pregnancy and marriage counselling, both inside and outside general practice. Doctors may argue that counsellors lack knowledge of a kind which has been included in their own training, and in consequence run the risk of damaging patients. We are well aware that there is potential for harm in counselling.

Where time has been taken to work at the respective roles of doctor and counsellor, and both work in collaboration, the overall benefit to the patient is marked. Our roles are constantly changing, and must, if we are to respond to the changing needs of people.

\section{Audrey Newsome \\ Director of Appointments and Counselling Service University of Keele \\ REFERENCES}

Crown, S. (ed) (1976) Psychosexual Problems. London: Academic Press.

ErIKson, E. H. (1968) Identity: Youth and Crisis. London: Faber \& Faber.

Newsome, A., Thorne, B. J., Wyld, K. L. (1973) Student Counselling Practice. University of London Press.

TOFFLER, A. (1971) Future Shock. London: Pan

\section{Psychiatry in the 1880s \\ Private Asylums \\ (from the Journal of Mental Science, 1879-80)}

From the Presidential Address by Dr. J. A. Lush, MP, (of Fisherton House, Salisbury)

'Between 1846 and 1879 the produce of a penny income tax has risen from $£ 750,000$ to $£ 1,750,000$, notwithstanding a much greater exemption; and the inhabited house duty has advanced in about a similar ratio; leaving little doubt that a considerable increase in the paying capabilities of the middle classes has been diffused throughout the country.

'Admitting the excellent management of the public institutions, I hold that there are, and ever will be, many who object to the quasi-publicity involved in them, and who will prefer the comparative privacy of Licensed Houses for their friends.

'There is undoubtedly an active although fractional party desirous of upsetting the present Acts, and the most vulnerable point of attack is found in the supposed interest of private proprietors in the reception and detention of unsuitable cases: but the true interest of a proprietor is in the reputation of his House, and with the present supervision and checks, the admission of improper cases is well nigh impossible; that is, if the same care and attention are bestowed upon Public Asylums by the Commissioners in Lunacy as my own experience teaches me they devote to private institutions; and that the tendency of the present system is in the direction of too early discharges.

'It is notorious that many Doctors refuse to sign certi- ficates in the clearest cases, from dread of responsibility, and of possible future annoyance; the Press seems eager to publish sensational accounts of supposed unjust detentions; while magistrates and judges, with one voice pit the so-called liberty of the subject against the danger to the common weal, to the detriment of the latter; and with another refuse to accept the plea of insanity in a large number of cases where prejudice or obtuseness alone can fail to detect it, and so inflict punishment upon irresponsible victims.

'Projects for boarding out paupers, and for the demolition of licensed houses are crudely put forward; and in the haste for cheap philanthropy, their authors set aside all considerations for the national weal.

'Not the diminution of Insanity, but license of the Lunatic, is inscribed upon the revolutionary banner, and its success is fraught with danger to the State as much as any other misguided fanaticism.'

In the discussion Dr. H. Monro (of Brooke House, Clapton) referred to Lord Shaftesbury's contrasting evidence to the Select Committees of 1859 and 1877.

'In 1859 there was hardly a word bad enough for him to use about private asylums, but when he gave evidence before the Select Committee in 1877, one of his last observations was that so high was his opinion of private asylums, that if it should please the Almighty to impose such an affiction upon him, he hoped he might be treated in a private asylum.' 